\title{
Trace Metal Requirements and Interactions in Symbiodinium kawagutii
}

\author{
Irene B. Rodriguez ${ }^{1}$ and Tung-Yuan Ho ${ }^{1,2 *}$ \\ ${ }^{1}$ Research Center for Environmental Changes, Academia Sinica, Taipei, Taiwan, ${ }^{2}$ Institute of Oceanography, National Taiwan \\ University, Taipei, Taiwan
}

Photosynthetic organisms need trace metals for various biological processes and different groups of microalgae have distinctive obligate necessities due to their respective biochemical requirements and ecological niches. We have previously shown that the dinoflagellate Symbiodinium kawagutii requires high concentrations of bioavailable Fe to achieve optimum growth. Here, we further explored the trace metal requirements of $S$. kawagutii with intensive focus on the effect of individual metal and its interaction with other divalent metals. We found that low Zn availability significantly decreases growth rates and results in elevated intracellular $\mathrm{Mn}, \mathrm{Co}, \mathrm{Ni}$, and $\mathrm{Fe}$ quotas in the dinoflagellate. The results highlight the complex interaction among trace metals in

OPEN ACCESS

Edited by:

Hongyue Dang,

Xiamen University, China

Reviewed by:

Thomas Krueger,

École Polytechnique Fédérale

de Lausanne, Switzerland

Roberto Iglesias-Prieto,

Pennsylvania State University,

United States

*Correspondence: Tung-Yuan Ho

tyho@gate.sinica.edu.tw

Specialty section:

This article was submitted to

Aquatic Microbiology,

a section of the journal

Frontiers in Microbiology

Received: 11 September 2017

Accepted: 22 January 2018

Published: 06 February 2018

Citation:

Rodriguez IB and Ho T-Y (2018)

Trace Metal Requirements

and Interactions in Symbiodinium

kawagutii. Front. Microbiol. 9:142.

doi: 10.3389/fmicb.2018.00142
S. kawagutii and suggest either metal replacement strategy to counter low Zn availability or enhanced uptake of other metals by non-specific divalent metal transporters. In this work, we also examined the Fe requirement of $S$. kawagutii using continuous cultures. We validated that 500 pM of Fe' was sufficient to support maximum cell density during steady state growth period either at 26 or $28^{\circ} \mathrm{C}$. This study shows that growth of S. kawagutii was limited by metal availability in the following order, Fe $>\mathrm{Zn}>\mathrm{Mn}>$ $\mathrm{Cu}>\mathrm{Ni}>\mathrm{Co}$. The fundamental information obtained for the free-living Symbiodinium shall provide insights into how trace metal availability, either from ambient seawater or hosts, affects growth and proliferation of symbiotic dinoflagellates and the interaction between symbiont and their hosts.

Keywords: trace metals, Symbiodinium, photosynthetic endosymbiont, coral bleaching, superoxide dismutase, zooxanthellae

\section{INTRODUCTION}

Trace metals are required by photosynthetic organisms for key processes including electron and oxygen transport, nutrient acquisition, DNA and RNA production and repair, antioxidative defense mechanisms, and many other pertinent biochemical functions (Raven et al., 1999; Sunda, 2012). Marine microalgae acquire bioavailable trace metals from their ambient environment through the action of uptake transporters and by releasing specialized compounds like siderophores or similar machineries (Morel and Price, 2003). The influence of trace metal availability on the growth of some model microalgae, mainly diatoms and coccolithophores, is well documented in literature (e.g., Sunda, 2012). However, there is a knowledge gap about trace metal requirements of endosymbiotic microalgae, such as the genus Symbiodinium, which constitutes the largest group of endosymbiotic photosynthetic dinoflagellates found in scleractinian corals 
and other cnidarians (Pochon et al., 2006; Stat et al., 2008). Owing to its unique ecological niche, the supply of trace metals and other nutrients available to Symbiodinium is largely controlled by its host. This entails a complex mechanism to achieve metal homeostasis to maintain critical concentrations of trace metals for necessary biological processes in both hosts and symbionts (Goiran et al., 1996; Rädecker et al., 2015).

In our previous work, we systematically investigated the requirement of Symbiodinium kawagutii for trace metal cofactors of superoxide dismutase (SOD) and found that it required the trace metals in the order: $\mathrm{Fe}>>\mathrm{Cu} / \mathrm{Zn} / \mathrm{Mn}>>\mathrm{Ni}$ (Rodriguez et al., 2016). We observed that the dinoflagellate growth was inhibited in treatments with low $\mathrm{Cu} / \mathrm{Zn}$ availability and these limiting conditions elevated the quotas of $\mathrm{Fe}, \mathrm{Mn}$, and $\mathrm{Co}$, suggesting that there may be functional complementarity between these metals. The absolute importance of $\mathrm{Cu}$ and $\mathrm{Zn}$ was not distinguished in our prior observations as the two metals were paired together in treatments. Here, batch culture experiments were carried out to evaluate the importance of each individual metal. In addition to $\mathrm{Cu}$ and $\mathrm{Zn}$, we also investigated in this study the influence of lack of related divalent metals, such as $\mathrm{Mn}, \mathrm{Co}$, or $\mathrm{Ni}$, on $\mathrm{S}$. kawagutii growth by varying their concentrations independently or coupled with conditions lacking $\mathrm{Cu}$ or $\mathrm{Zn}$. We also further interrogated the importance of $\mathrm{Fe}$ availability on dinoflagellate growth using continuous cultures where S. kawagutii was kept in steady state growth conditions at different levels of Fe supply. The use of continuous cultures allowed us to investigate the influence of Fe availability on the uptake of other divalent trace metals under the growth temperature of $26^{\circ} \mathrm{C}$ and at a slightly elevated temperature of $28^{\circ} \mathrm{C}$.

In this work, we set out to understand the trace metal requirements of free-living $S$. kawagutii in culture and how the supply of a specific trace metal, e.g., Zn, may influence uptake of other trace metals. Our results may provide information on how bioavailability of these micronutrients affects the growth of free-living dinoflagellates and also shed light on how trace metal supply, which is largely controlled by the host, may dictate the growth of symbiotic photosynthetic organisms.

\section{MATERIALS AND METHODS}

\section{General Culture Conditions for Batch Culture Experiments}

Non-axenic Symbiodinium kawagutii (hereafter referred to as S. kawagutii) was obtained from National Center for Marine Algae and Microbiota. The strain, denoted as CCMP2468, was isolated from the scleractinian coral Montipora verrucosa and belongs to phylogenetic clade F1. In this work, S. kawagutii was grown in trace metal defined medium (Rodriguez et al., 2016) modified from the original L1 recipe (Guillard and Hargraves, 1993). Surface seawater collected from Taiwanese South East Asia Time Series Station (SEATS, $18^{\circ} \mathrm{N} 116^{\circ} \mathrm{E}$ ) was used for culture medium preparation. Seawater was first passed through a column packed with Chelex- $100^{\circledR}$ resin to remove background trace metal contents and filter-sterilized using a $0.22 \mu \mathrm{m}$ pore size filter prior to use. All batch cultures were carried out in triplicates and were kept in growth chambers with temperature controlled at $26^{\circ} \mathrm{C}$. The light was supplied at photon flux density of $680 \mu \mathrm{mol}$ quanta $\mathrm{m}^{-2} \mathrm{~s}^{-1}$ and operated at a 12:12 $\mathrm{h}$ day:night squarewave photoperiod. Initial nitrate and phosphate concentrations were $800 \mu \mathrm{M}$ and $50 \mu \mathrm{M}$, respectively. A mixture of B-vitamins, composed of thiamine, biotin, and cyanocobalamin, was added to culture media to achieve final concentrations of 300, 2.0, and $0.40 \mathrm{nM}$, respectively. All necessary procedures were carried out in a class-100 trace metal clean laboratory. All materials for culturing and other relevant procedures were washed using $2 \%$ Micro- $90^{\circledR}$ solution, rinsed, washed with $10 \% \mathrm{HCl}$ solution, and rinsed thoroughly with ultrapure water prepared using a Milli-Q system.

\section{Trace Metal Conditions for Batch Culture Experiments}

We carried out two sets of batch culture experiments using $500 \mathrm{ml}$ polycarbonate (PC) bottles. In both sets of experiments, Fe was supplied at $250 \mathrm{nM}$ total dissolved concentration corresponding to an expected inorganic $\mathrm{Fe}$ concentration $\left(\mathrm{Fe}^{\prime}\right)$ of $1.25 \mathrm{nM}$ upon addition of $20 \mu \mathrm{M}$ ethylenediaminetetraacetic acid (EDTA). Bioavailability of trace metals in cultures is dictated by the non-chelated or inorganic metal concentration $\left(\mathrm{M}^{\prime}\right)$ and this was attained in culture medium by adding EDTA. All of the expected inorganic metal concentrations mentioned in this study were calculated using MineQL version 4.0 (Westall et al., 1976).

We first focused on the interactive effects of $\mathrm{Cu}, \mathrm{Zn}, \mathrm{Mn}$, and $\mathrm{Co}$ on the dinoflagellate growth under higher $\mathrm{Cu}$ and lower Mn concentrations compared to levels used in our prior work. We increased the $\mathrm{Cu}$ and lowered the $\mathrm{Mn}$ concentrations to better simulate natural conditions. We included $\mathrm{Co}$ as a metal of interest to investigate interaction between $\mathrm{Co}, \mathrm{Cu}$, and $\mathrm{Zn}$ due to prior observations that intracellular Co content was elevated in treatments without $\mathrm{Cu} / \mathrm{Zn}$ (Rodriguez et al., 2016). In this set of experiments, the control cultures contained total dissolved concentrations equivalent to $100 \mathrm{nM}$ for $\mathrm{Cu}$ and $\mathrm{Zn}$, and $10 \mathrm{nM}$ for $\mathrm{Mn}$ and $\mathrm{Co}$, resulting in expected inorganic metal concentrations of $5.0 \mathrm{pM} \mathrm{Cu}^{\prime}, 125 \mathrm{pM} \mathrm{Zn}^{\prime}, 4.2 \mathrm{nM} \mathrm{Mn}^{\prime}$, and 20 $\mathrm{pM} \mathrm{Co}^{\prime}$, respectively. We carried out other treatments where one or a pair of metals was omitted in the culture medium, which was denoted by a minus sign before the element symbol. The summary of trace metal concentrations in different treatments in this set of experiments is presented in Table 1.

We then carried out another experiment to focus on interactive effects of $\mathrm{Cu}, \mathrm{Zn}$, and $\mathrm{Mn}$ under relatively low $\mathrm{Cu}$ and $\mathrm{Zn}$ concentrations, which were demonstrated in the previous set of experiments to support growth of $S$. kawagutii. The control cultures were amended with total dissolved concentrations of $\mathrm{Cu}, \mathrm{Zn}$, and $\mathrm{Mn}$ at $10 \mathrm{nM}$, corresponding to expected inorganic concentrations of $0.50 \mathrm{pM}, 12.5 \mathrm{pM}$, and $4.2 \mathrm{nM}$, respectively. We also included additional treatments to validate or further examine the effects of low Fe (50 nM Fe or $250 \mathrm{pM} \mathrm{Fe}^{\prime}$ ) and low $\mathrm{Zn}(2$

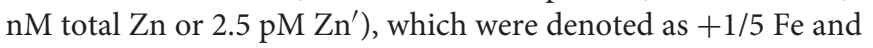
$+1 / 5 \mathrm{Zn}$. The summary of trace metal concentrations in different treatments for this set is presented in Table 2. 


\section{Iron Experiments in Continuous Cultures}

To further study the influence of Fe availability on dinoflagellate growth, we kept $S$. kawagutii at steady-state growth using a continuous culture system with trace metal defined medium. We subjected the dinoflagellate to three different total dissolved Fe concentrations equivalent to 50,100 , and $250 \mathrm{nM}$ resulting in $250 \mathrm{pM}, 500 \mathrm{pM}$, and $1.25 \mathrm{nM}$ of $\mathrm{Fe}^{\prime}$, respectively. The other trace metals were supplied at total concentrations of $10 \mathrm{nM}$ for $\mathrm{Cu}, \mathrm{Zn}, \mathrm{Mn}, \mathrm{Ni}$, and $\mathrm{Co}$ resulting in expected inorganic metal concentrations of $0.50 \mathrm{pM} \mathrm{Cu}^{\prime}, 12.5 \mathrm{pM} \mathrm{Zn}^{\prime}, 4.2 \mathrm{nM} \mathrm{Mn}^{\prime}, 6.7 \mathrm{pM}$ $\mathrm{Ni}^{\prime}$, and $20 \mathrm{pM} \mathrm{Co}$, respectively. Nitrate, phosphate, vitamin B mixture, and EDTA were supplied at equivalent concentrations as in batch cultures.

For most of the growth period, the cultures were subjected to ambient temperature of $26^{\circ} \mathrm{C}$. To elucidate the interactive effects of $\mathrm{Fe}$ availability and increase in temperature, the cultures were subjected to an elevated temperature $\left(28^{\circ} \mathrm{C}\right)$ for the period covering days 17-23, after which period the temperature was reverted back to $26^{\circ} \mathrm{C}$. The cultures were kept in growth chambers with light supplied at photon flux density of $600 \mu \mathrm{mol}$ quanta $\mathrm{m}^{-2} \mathrm{~s}^{-1}$ operated at a $12: 12 \mathrm{~h}$ day:night square-wave photoperiod. The system constituted of duplicate $1 \mathrm{~L}$ PC magnetic culture vessels fitted with inflow and outflow Teflon tubing maintained at equal rates of 0.270 $\mathrm{L}$ day $^{-1}$. The source medium was introduced from a $10 \mathrm{~L}$ PC carboy with polypropylene screw cap. The outflow was connected to $500 \mathrm{~mL}$ PC containers as algal waste/sampling containers. Continuous stirring of source medium and duplicate culture vessels was done using magnetic stirrers. The rates for both the inflow and outflow were precisely controlled using a multichannel peristaltic pump (IPC 8, Ismatec ${ }^{\circledR}$, Germany). Syringe filters with $0.22 \mu \mathrm{m}$ pore size were fitted in all containers including source, magnetic culture vessels, and sampling containers to maintain atmospheric pressure

TABLE 1 | Trace metal concentrations in batch cultures to investigate the interactive effects of Cu, Zn, Mn, and Co on Symbiodinium kawagutii growth.

\begin{tabular}{|c|c|c|c|c|c|c|c|}
\hline Treatment number & Treatment label & \multicolumn{6}{|c|}{ Metal availability } \\
\hline 2 & $-\mathrm{Cu}$ & - & 4.2 & 125 & 20 & 1.25 & 6.7 \\
\hline 3 & $-\mathrm{Mn}$ & 5 & - & 125 & 20 & 1.25 & 6.7 \\
\hline 4 & $-Z n$ & 5 & 4.2 & - & 20 & 1.25 & 6.7 \\
\hline 7 & $+1 / 10 \mathrm{Zn}$ & 5 & 4.2 & 12.5 & 20 & 1.25 & 6.7 \\
\hline 8 & $-\mathrm{Cu} / \mathrm{Mn}$ & - & - & 125 & 20 & 1.25 & 6.7 \\
\hline 9 & $-\mathrm{Cu} / \mathrm{Co}$ & - & 4.2 & 125 & - & 1.25 & 6.7 \\
\hline 10 & $-M n / Z n$ & 5 & - & - & 20 & 1.25 & 6.7 \\
\hline 11 & $-\mathrm{Mn} / \mathrm{Co}$ & 5 & - & 125 & - & 1.25 & 6.7 \\
\hline
\end{tabular}

Control cultures were supplied with trace metals at total dissolved concentrations equivalent to $100 \mathrm{nM}$ for $\mathrm{Cu}$ and $\mathrm{Zn}, 10 \mathrm{nM}$ for Mn, Ni, and Co, and $250 \mathrm{nM}$ for Fe

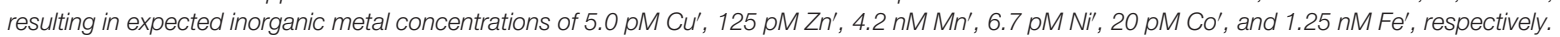

TABLE 2 | Trace metal concentrations in batch cultures to investigate the interactive effects of $\mathrm{Cu}, \mathrm{Zn}$, and $\mathrm{Mn}$ on S. kawagutii growth.

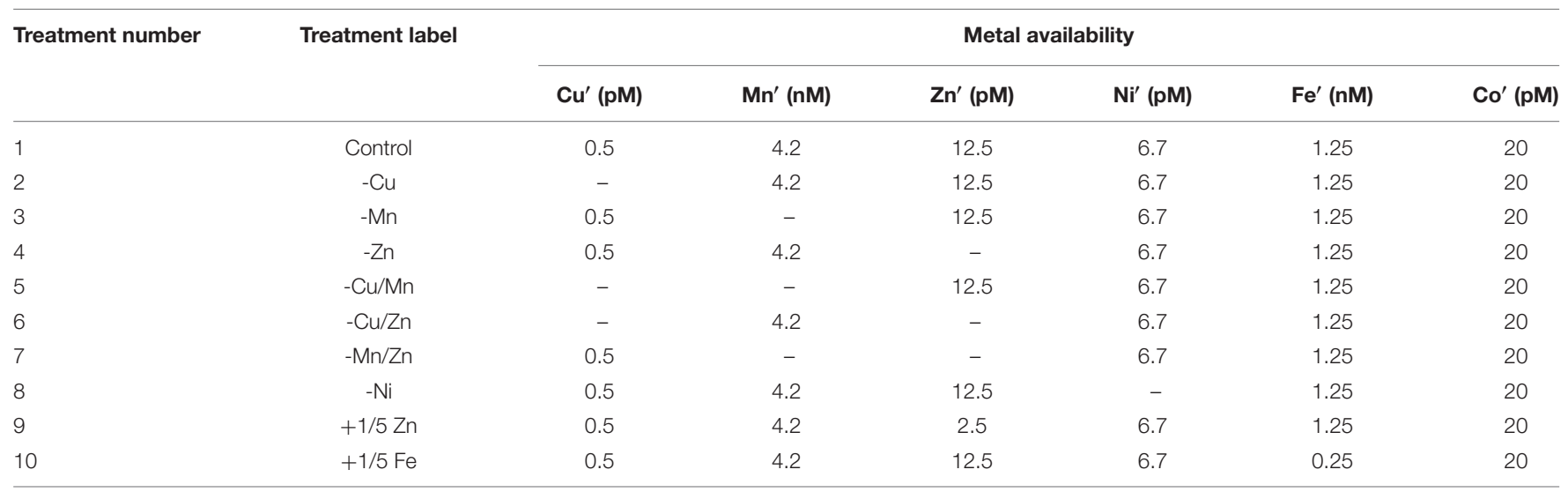

The treatments were designed to contain lower $\mathrm{Cu}$ and $\mathrm{Zn}$ concentrations than in the preceding experiment. Control cultures were supplied with trace metals at total dissolved concentrations equivalent to $10 \mathrm{nM}$ for $\mathrm{Cu}, \mathrm{Zn}, \mathrm{Mn}$, Ni, and Co, and $250 \mathrm{nM}$ for Fe resulting in expected inorganic metal concentrations of $0.5 \mathrm{pM}$ Cu', 12.5 pM Zn', 4.2 nM Mn', 6.7 pM Ni', 20 pM Co', and 1.25 nM Fe', respectively. 
equilibrium between the headspace inside the containers and the ambient surroundings.

\section{Assessment of Growth Rates and Trace Metal Quotas}

The growth of S. kawagutii was monitored by checking the change in cell density over a period spanning 17 days for batch cultures and 29 days for continuous cultures using a Beckman Coulter Counter Multisizer 3 outfitted with a $100 \mu \mathrm{m}$ aperture tube. Particle size counting was set within the range 3-8 $\mu \mathrm{m}$ to monitor S. kawagutii cells in culture and eliminate possible interference from smaller organisms. There are other methods to monitor changes in cell density but the use of a Coulter Counter offers ease of use combined with excellent precision in measurements that has been demonstrated in dinoflagellates (Krediet et al., 2015). The growth rate in batch cultures was estimated while cells were in exponential phase of growth, typically from days 4 to 10 , to ensure minimum contribution from other organisms that may co-exist with $S$. kawagutii in culture. The growth rate in continuous cultures was set at 0.27 day $^{-1}$ during the steady state period of growth using a fixed flow rate of $0.27 \mathrm{~L} \mathrm{day}^{-1}$ for $1 \mathrm{~L}$ culture bottle (Herbert et al., 1956; Dunstan and Menzel, 1971; Touloupakis et al., 2015).

Intracellular trace metal quotas in batch cultures were determined in cells collected during the exponential growth period. In continuous cultures, samples were collected for a total of six times to cover the establishment phase and the steady state growth period. Cells for metal quota determination were collected by filtration onto acid-washed $25 \mathrm{~mm}$ PC filters with $2 \mu \mathrm{m}$ pore size. The cells were quickly rinsed with ultrapure water three times and then acid-digested prior to elemental determination using a high resolution ICPMS (Element XR, Thermo Scientific). Metal quotas were normalized against phosphorus as the biomass indicator (Ho et al., 2003). Procedural filter blanks were subjected to the same digestion, dilution, and analysis. The blank values were subtracted from sample measurements. The detailed information of analytical procedures was described in previous studies (Ho et al., 2003; Ho, 2013).

\section{Statistical Analyses}

One-way analysis of variance (ANOVA) was conducted to determine statistical differences between treatments (post hoc Tukey HSD, $p<0.05$; SPSS).

\section{RESULTS}

\section{Effect of Trace Metals on S. kawagutii Growth}

The control cultures of $S$. kawagutii achieved a growth rate of $0.55 \pm 0.03$ day $^{-1}$ and a maximum biomass of about $2.5 \times 10^{5}$ cells ml $^{-1}$ after 14 days of incubation (Figure $\mathbf{1 A}$ and Supplementary Figure 1). Specific growth rates for treatments showing independent effect of a metal of interest and interactive effects of a pair of metals are presented in Figure 1. Among single metal treatments, there was a statistically significant difference between growth rates as determined by one-way ANOVA $\left(F_{6,14}=46.22, p<0.0001\right)$. Compared to the growth rate attained by control cultures, the treatment - Co attained a comparable rate of $0.57 \pm 0.04 \mathrm{day}^{-1}$. Other treatments also had comparable growth rates to that of the control including the cultures with 10 -fold lower $\mathrm{Cu}$ or $\mathrm{Zn}$ concentrations. The omission of either $\mathrm{Cu}$ or $\mathrm{Mn}$ resulted in lower rates that were in the same magnitude, $0.42 \pm 0.01$ day $^{-1}$ and $0.41 \pm 0.01$ $\mathrm{day}^{-1}$, respectively. Among all treatments, the cultures lacking $\mathrm{Zn}$ had the lowest growth rate of $0.24 \pm 0.03 \mathrm{day}^{-1}$. The effect of lack of a pair of metals on S. kawagutii growth is presented in Figure 1B. The cultures without $\mathrm{Cu} / \mathrm{Mn}$ had a growth rate $\left(0.31 \pm 0.01 \mathrm{day}^{-1}\right)$ that was significantly lower than in both $\mathrm{Cu}$ and $-\mathrm{Mn}$ treatments $\left(F_{2,6}=113.4, p<0.0001\right)$. The cultures without $\mathrm{Mn} / \mathrm{Zn}$ had a rate $\left(0.20 \pm 0.03 \mathrm{day}^{-1}\right)$ that was lower than in -Mn treatment but was comparable to the value in $\mathrm{Zn}$ treatment as determined by one-way ANOVA $\left(F_{2,6}=11.62\right.$, $p=0.009$ ). For all cultures without $\mathrm{Co}$ and either one of $\mathrm{Cu}, \mathrm{Mn}$, or $\mathrm{Zn}$, the growth rates were comparable to treatments lacking only $\mathrm{Cu}\left(F_{2,6}=20.16, p=0.002\right), \mathrm{Mn}\left(F_{2,6}=25.74, p=0.001\right)$ or $\mathrm{Zn}\left(F_{2,6}=63.38, p<0.0001\right)$, respectively.

The metal quotas showed that in the control treatment, Fe had the highest intracellular concentration followed by $\mathrm{Mn}, \mathrm{Zn}, \mathrm{Cu}$, and then Co (Figure 2). As expected, intracellular metal quotas were low for metals that were designed to be omitted in culture medium. For example, $\mathrm{Zn}$ quotas were lower in treatments lacking $\mathrm{Zn}$ including $-\mathrm{Zn},-\mathrm{Mn} / \mathrm{Zn}$, and $-\mathrm{Zn} / \mathrm{Co}\left(F_{11,48}=59.82\right.$, $p<0.0001$ ) while $\mathrm{Mn}$ quotas were lower in cultures without $\mathrm{Mn}$ including the treatments $-\mathrm{Mn},-\mathrm{Cu} / \mathrm{Mn},-\mathrm{Mn} / \mathrm{Zn}$, and $-\mathrm{Mn} / \mathrm{Co}$. It was notable that $\mathrm{Fe}$ quotas $\left(F_{11,48}=43.83, p<0.0001\right)$, as well as Co $\left(F_{11,48}=110.0, p<0.0001\right)$ and Mn quotas $\left(F_{11,48}=120.0, p<0.0001\right)$ whenever either of these metals was supplied, were significantly elevated in treatments lacking $\mathrm{Zn}$. However, intracellular Fe content was not elevated in the treatment with $+1 / 10 \mathrm{Zn}$.

In the subsequent experiment, although the control treatment had lower $\mathrm{Cu}$ and $\mathrm{Zn}$ concentrations, control S. kawagutii cultures still attained a growth rate of $0.57 \pm 0.01 \mathrm{day}^{-1}$ and reached $8 \times 10^{5}$ cells ml $^{-1}$ after 14 days of incubation (Figure 3A and Supplementary Figure 2). There was a statistically significant difference between growth rates among single metal treatments as determined by one-way ANOVA $\left(F_{6,14}=36.70, p<0.0001\right)$. It was apparent that cultures lacking $\mathrm{Zn}$ had the lowest growth rate of $0.15 \pm 0.07$ day $^{-1}$ that was significantly different from all other treatments. The treatment with $1 / 5 \mathrm{Fe}$ had a rate of $0.32 \pm 0.06 \mathrm{day}^{-1}$, which was comparable to the treatment with $1 / 5 \mathrm{Zn}\left(0.35 \pm 0.03 \mathrm{day}^{-1}\right)$. Compared with growth rate of control cultures, the treatments $-\mathrm{Cu},-\mathrm{Mn}$, and $-\mathrm{Ni}$ all reflected lower rates that were in the range $0.43-0.45 \mathrm{day}^{-1}$. In terms of intracellular content, it was observed again that quotas for specific metals in treatments designed to omit them reflected low values for the metals. For instance, $\mathrm{Zn}$ quota was low in the $\mathrm{Zn}$ treatment $\left(F_{6,28}=18.92, p<0.0001\right)$ and $\mathrm{Cu}$ quota was low in the $-\mathrm{Cu}$ treatment $\left(F_{6,28}=25.71, p<0.0001\right.$; Figure 3B $)$. It was also observed that $\mathrm{Mn}\left(F_{6,28}=285.0, p<0.0001\right)$, Co $\left(F_{6,28}=65.01, p<0.0001\right), \mathrm{Ni}\left(F_{6,28}=125.8, p<0.0001\right)$, and Fe 

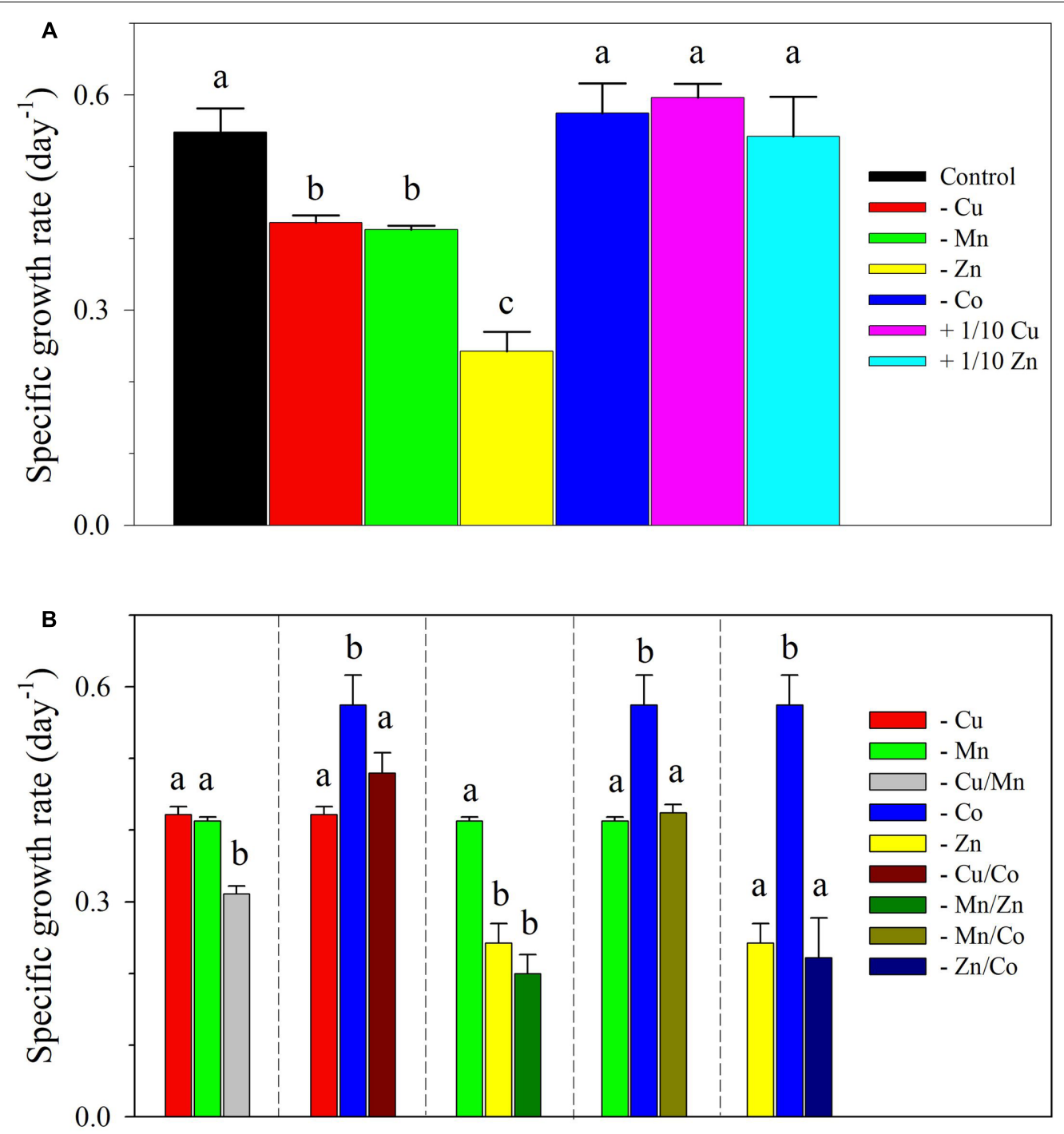

\section{Treatment}

FIGURE 1 | Specific growth rates of Symbiodinium kawagutii subjected to different trace metal conditions. (A) Independent effect of lack or lower concentration of a

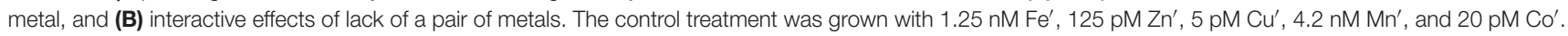
The values represent means $\pm S D(N=3, P<0.05$, ANOVA, post hoc Tukey HSD).

$\left(F_{6,28}=368.2, p<0.0001\right)$ quotas were elevated in the treatment lacking $\mathrm{Zn}$. For treatments elucidating the interactive effects of a pair of metals, the growth curves, rates, and intracellular metal quotas are summarized in Supplementary Figure 3. The growth rates of treatments lacking $\mathrm{Zn}$ in combination with either $\mathrm{Cu}$ $\left(F_{2,6}=27.18, p=0.001\right)$ or $\mathrm{Mn}\left(F_{2,6}=34.31, p=0.001\right)$ were comparable to the rate observed in the treatment lacking $\mathrm{Zn}$.

\section{Influence of Fe Availability on S. kawagutii Growth in Continuous Cultures}

The growth curves of the dinoflagellate in continuous cultures are presented in Figure 4A. In terms of cell density, the results show that $1.25 \mathrm{nM} \mathrm{Fe}^{\prime}$ supported high cell density at the level of $10^{6}$ cells $\mathrm{ml}^{-1}$ during the steady state growth period, which was attained after about 12 days. The cultures supplied with 500 pM $\mathrm{Fe}^{\prime}$ also achieved comparable cell density after 19 days while the cultures amended with 250 pM Fe' only reached about $2 \times 10^{5}$ cells $\mathrm{ml}^{-1}$. The increase in growth temperature from 26 to $28^{\circ} \mathrm{C}$ for the period covering days 17-23 did not result in observable changes in cell density for cultures subjected to $500 \mathrm{pM}$ or $1.25 \mathrm{nM} \mathrm{Fe}$. Intracellular metal quotas in cells were evaluated at different times during the incubation period (Figure 4B). Fe quotas in cultures with $250 \mathrm{pM} \mathrm{Fe}^{\prime}$ were within the range 14.9$15.4 \mathrm{mmol} \mathrm{mol}^{-1} \mathrm{P}$ during the steady state growth period from days 10 to 17 . In cultures with $500 \mathrm{pM} \mathrm{Fe}^{\prime}$, the Fe quotas were within the range $7.1-10.1 \mathrm{mmol} \mathrm{mol}^{-1} \mathrm{P}$ for the period covering 


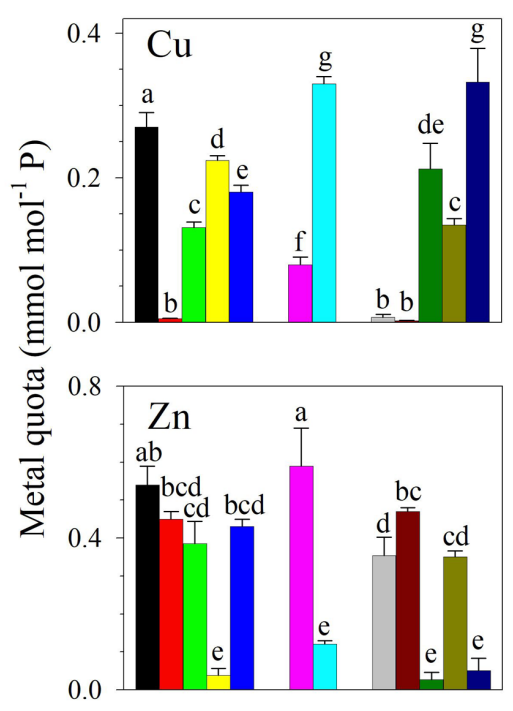

0.0
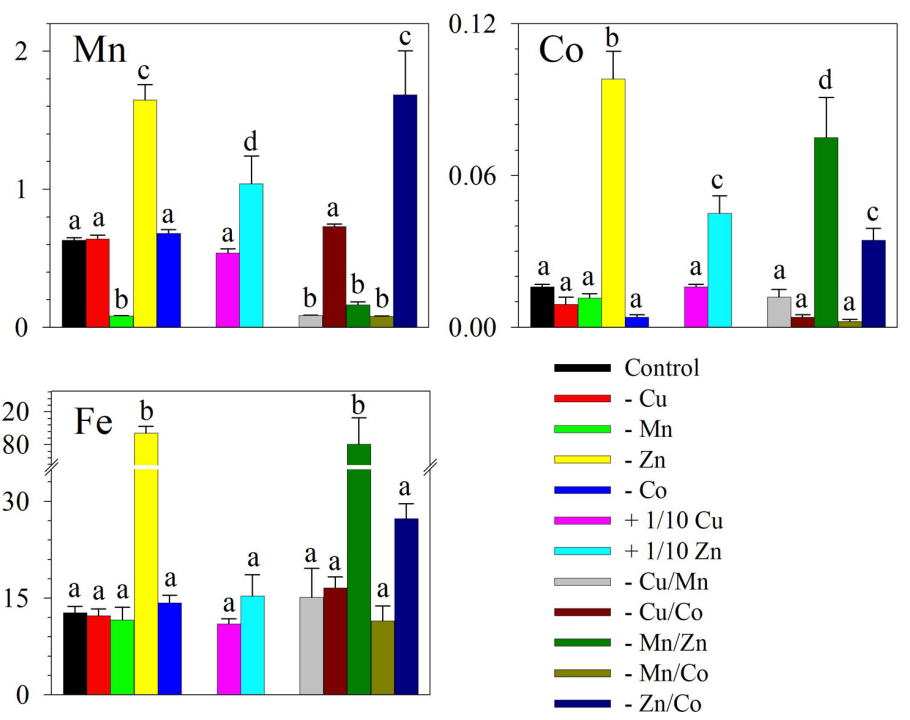

Treatment

FIGURE 2 | Intracellular trace metal quotas of $\mathrm{S}$. kawagutii subjected to different trace metal conditions to investigate the interactive effects of Cu, Zn, Mn, and Co. The control treatment was grown with $1.25 \mathrm{nM} \mathrm{Fe}^{\prime}, 125 \mathrm{pM} \mathrm{Zn}^{\prime}, 5 \mathrm{pM} \mathrm{Cu}^{\prime}, 4.2 \mathrm{nM} \mathrm{Mn}$, and $20 \mathrm{pM} \mathrm{Co}^{\prime}$. The values represent means $\pm \mathrm{SD}(N=3, P<0.05$, ANOVA, post hoc Tukey HSD).

days 18-28. The cultures with $1.25 \mathrm{nM} \mathrm{Fe}^{\prime}$ showed the longest steady state period from days 12 to 29 wherein Fe quotas were observed at 15.0 and $15.8 \mathrm{mmol} \mathrm{mol}^{-1} \mathrm{P}$ before stabilizing in the range $8.4-9.1 \mathrm{mmol} \mathrm{mol}^{-1} \mathrm{P}$. There was significant increase in $\mathrm{Zn}$ quotas corresponding to the period of temperature change in the treatment with $250 \mathrm{pM} \mathrm{Fe}$, which were not observed in cultures provided with higher Fe availability. Mn quotas varied slightly among different treatments, with higher values observed in the treatment with $250 \mathrm{pM} \mathrm{Fe}^{\prime}$ ranging from 0.51 to $0.73 \mathrm{mmol}$ $\mathrm{mol}^{-1} \mathrm{P}$ compared to $0.43-0.56$ and $0.29-0.54 \mathrm{mmol} \mathrm{mol}^{-1} \mathrm{P}$ in cultures supplied with 500 and 1,250 pM Fe', respectively. An increasing trend was observed for $\mathrm{Cu}$ quotas in treatments with higher Fe availability, albeit changes were not significant for most. For Ni quotas, relatively lower values were observed in cultures with $1.25 \mathrm{nM} \mathrm{Fe}^{\prime}$ compared to that in 250 and $500 \mathrm{pM} \mathrm{Fe}^{\prime}$ cultures. Co quotas showed higher values in 250 pM Fe' cultures compared to the two treatments with relatively high $\mathrm{Fe}^{\prime}$.

\section{DISCUSSION}

\section{Effect of Trace Metal Availability on S. kawagutii Growth}

In our previous work on $S$. kawagutii, we coupled $\mathrm{Cu}$ and $\mathrm{Zn}$ together in treatments due to their coexistence in SOD. The coupled effect of $\mathrm{Cu}$ and $\mathrm{Zn}$ on the dinoflagellate growth was significant but it was difficult to distinguish their individual importance (Rodriguez et al., 2016). By varying the availability of $\mathrm{Cu}$ or $\mathrm{Zn}$ individually, the results of this study demonstrate that $\mathrm{Zn}$ has a stronger influence on the dinoflagellate growth compared to $\mathrm{Cu}$. This was evidenced by lower growth rates observed in $-\mathrm{Zn}$ treatments than in $-\mathrm{Cu}$ treatments, either independently or in combination with lack of either Mn or Co (Figures 1, 3 and Supplementary Figure 3). These results indicate that the reduced growth observed in the $-\mathrm{Cu} / \mathrm{Zn}$ treatment in our previous work (Rodriguez et al., 2016) and observed again here was mainly due to $\mathrm{Zn}$ limitation. The results also place $\mathrm{Zn}$ after Fe and make it the second most needed trace metal by S. kawagutii. The essential role of $\mathrm{Zn}$ is expected for dinoflagellates because $\mathrm{Zn}$ is a cofactor in carbonic anhydrase, alkaline phosphatase, RNA polymerase, reverse transcriptase, and other enzymes (Raven et al., 1999; Sunda, 2012). In addition to - $\mathrm{Zn}$ treatments, we also evaluated the minimum $\mathrm{Zn}$ concentration that will support maximum growth of $S$. kawagutii by growing the cells with 12.5 $\mathrm{pM} \mathrm{Zn}^{\prime}$, one tenth of the concentration used in the control $(+1 / 10 \mathrm{Zn}$, Table 1 and Figure 1A). The growth rate observed in $+1 / 10 \mathrm{Zn}$ treatment was comparable to that in control cultures, indicating that $12.5 \mathrm{pM} \mathrm{Zn^{ \prime }}$ was sufficient for optimal growth. In brief, our results show that $\mathrm{Zn}$ deficiency may negatively affect the dinoflagellate growth and highlight the need to investigate bioavailable $\mathrm{Zn}$ concentrations in ambient seawater surrounding coral reef areas, as well as understand the mechanism for $\mathrm{Zn}$ uptake and trafficking within the coral holobiont.

Copper may serve as a micronutrient or a toxic agent for microalgae, depending on its bioavailable concentration in seawater (Festa and Thiele, 2011). Indeed, an early report has established the negative effects of $\mathrm{Cu}$ on marine dinoflagellates and posited that high $\mathrm{Cu}$ concentrations were probably arresting cell division or causing change in cell metabolism (Saifullah, 1978). Also, elevated levels of labile $\mathrm{Cu}$ have been shown to impede growth of the dinoflagellates Amphidinium carterae and Prorocentrum micans as well as reduce protein production in the latter (Lage et al., 1994). On the other side of its toxic role, $\mathrm{Cu}$ is pertinent in the action of transcriptional regulators, 

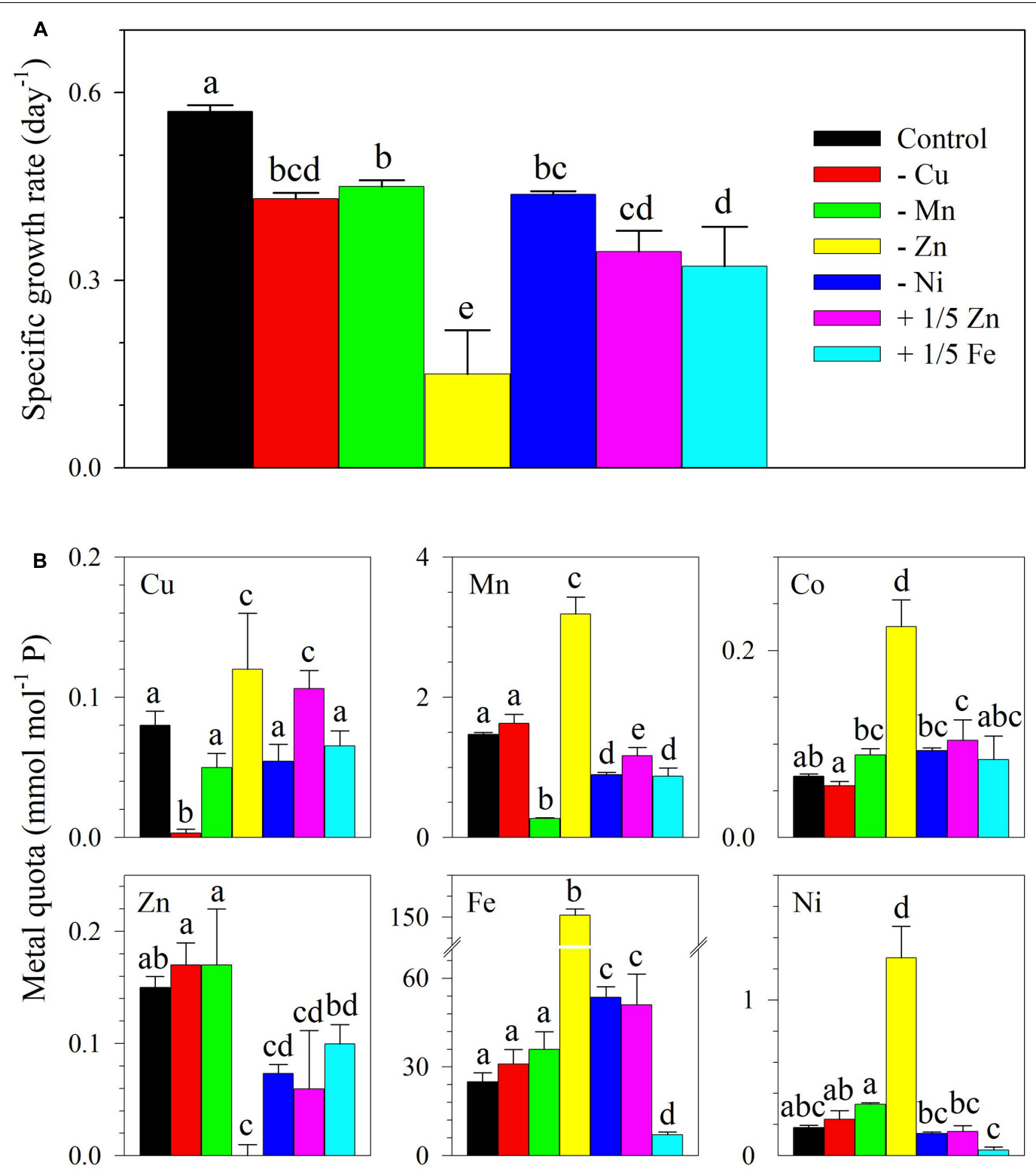

Treatment

FIGURE 3 | (A) Specific growth rates and (B) trace metal quotas of $S$. kawagutii subjected to different trace metal availability. The control treatment was grown with

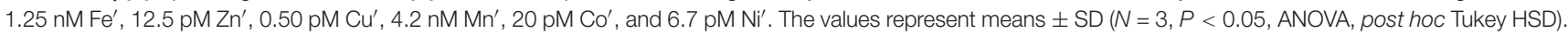

oxidoreductases, and in chaperones or storage (Festa and Thiele, 2011). Total dissolved $\mathrm{Cu}$ concentrations can reach to $45 \mathrm{nM}$ in riverine and submarine groundwater discharge near populous regions (Donat et al., 1994). Cu is also highly abundant and soluble in anthropogenic aerosols, which may be transported to offshore coral reef areas seasonally (Sholkovitz et al., 2010). We deemed it necessary to elucidate the optimum range of $\mathrm{Cu}$ supply that permits dinoflagellate growth. The inorganic $\mathrm{Cu}$ concentration used in our previous work was relatively low, $0.50 \mathrm{pM}$, compared to inorganic concentrations of $\mathrm{Fe}, \mathrm{Mn}$, and $\mathrm{Zn}$, which were 50-1,250 pM, $42 \mathrm{nM}$, and $125 \mathrm{pM}$, respectively
(Rodriguez et al., 2016). In this study, we initially increased $\mathrm{Cu}^{\prime}$ to $5.0 \mathrm{pM}$ and also carried out a treatment with 10 -fold lower $\mathrm{Cu}^{\prime}$ (Table 1 and Figure 1A). Our results clearly indicate that $5 \mathrm{pM} \mathrm{Cu}$ did not inhibit growth of $S$. kawagutii and that $0.50 \mathrm{pM} \mathrm{Cu} \mathrm{Cu}^{\prime}$ was sufficient to support favorable growth of the dinoflagellate (Figure 1A). When grown in - $\mathrm{Cu}$ conditions, with potential carry-over $\mathrm{Cu}$ from the inoculum, the dinoflagellate was still able to attain high cell density albeit at a much slower growth rate. These results indicate that the dinoflagellate has an obligate need for $\mathrm{Cu}$ that may be met even with low $\mathrm{Cu}$ availability. 


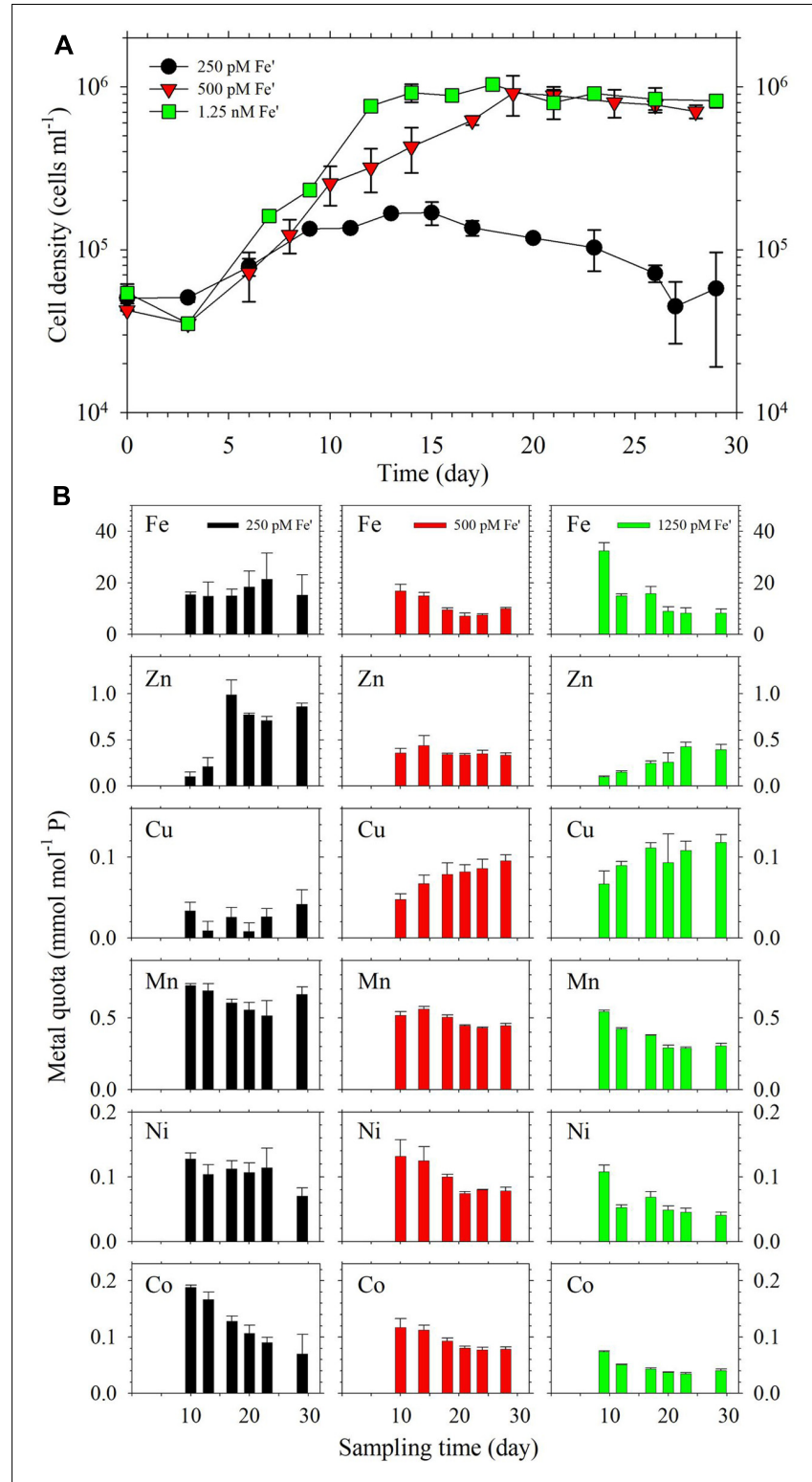

FIGURE 4 | (A) Growth curves and (B) intracellular metal quotas of S. kawagutii subjected to different Fe availability in continuous culture conditions. The other trace metals were supplied at the following concentrations: 12.5 pM Zn', 0.50 pM Cu', 4.2 nM Mn', 20 pM Co', and 6.7 $\mathrm{pM} \mathrm{Ni}$. Error bars represent average deviation of duplicate cultures.

Manganese is mainly utilized in the oxygen-evolving complex of PSII as well as in maintenance of chloroplast structure in photosynthetic organisms. A study on Amphidinium sp. found that Mn availability was positively correlated with growth rate, maximal photochemical efficiency, and Mn-SOD production of the dinoflagellate (Cao et al., 2011). Our previous study shows that $42 \mathrm{nM} \mathrm{Mn}$ ' was sufficient for $S$. kawagutii to reach maximum growth. In this study, we used $4.2 \mathrm{nM} \mathrm{Mn}^{\prime}$ in the control treatment, one tenth of the concentrations used in our previous work to better simulate the Mn concentrations in the natural environment (Rodriguez et al., 2016). The results show that 4.2
$\mathrm{nM} \mathrm{Mn}$ ' was sufficient to support S. kawagutii growth. Thus, we used this concentration in subsequent set of experiments. Mn exhibits relatively high dissolved concentrations in oceanic surface water, with dissolved concentrations generally ranging from 2 to $10 \mathrm{nM}$ (Landing and Bruland, 1987). It is thus unlikely that Mn would become a limiting factor for S. kawagutii growth in natural environments. In this work, the dinoflagellate was also grown under lack of both $\mathrm{Cu}$ and $\mathrm{Mn}$ in the $-\mathrm{Cu} / \mathrm{Mn}$ treatment (Figure 1B and Supplementary Figure 3). In both instances, the growth rate attained by the $-\mathrm{Cu} / \mathrm{Mn}$ treatment was always lower than in both the $-\mathrm{Cu}$ and $-\mathrm{Mn}$ treatments indicating a synergistic negative effect of lack of both metals on $S$. kawagutii growth. This observation certainly warrants further study.

We also carried out a treatment lacking $\mathrm{Ni}$ and the result showed that lack of $\mathrm{Ni}$ resulted in significantly lower growth rate than in control cultures $(0.43 \pm 0.01, p=0.001$, Figure 3A). This finding was contradictory with our prior observation that $\mathrm{Ni}$ only slightly affects the growth of the dinoflagellate (Rodriguez et al., 2016). The disparity in results may have been due to interactive effects of trace metals supplied at specific concentrations. In our prior work, $\mathrm{Zn}, \mathrm{Mn}$, and $\mathrm{Ni}$ were supplied at 10-fold higher concentrations compared to levels used in this set of treatments (Table 2). The relatively high concentrations of trace metals used in our prior work may have fully or partially replaced the requirement for a specific metal in treatments, e.g., in -Ni conditions (Rodriguez et al., 2016). In terms of Co requirement, we carried out four treatments lacking Co independently or paired with $\mathrm{Zn}$, $\mathrm{Cu}$, or $\mathrm{Mn}$ (Table $\mathbf{1}$ and Figure 1). For the independent effect of -Co, we did not observe significant influence on $S$. kawagutii growth. When paired with other metals, the results show that the growth was more affected by availability of the other metal rather than Co. For instance, growth of $\mathrm{Mn} / \mathrm{Co}$ cultures was similar to the growth performance of Mn cultures (Figure 1B). These results suggest that Co was required at low concentrations or it may not be essential for S. kawagutii growth. Overall, by compiling the results obtained from both sets of experiments, trace metal requirements of S. kawagutii follows the order: $\mathrm{Fe}>\mathrm{Zn}>\mathrm{Mn}>\mathrm{Cu}>$ $\mathrm{Ni}>$ Co. Trace metal concentrations in the environment may be influenced by various processes including natural and anthropogenic activities with the latter largely viewed as a major factor determining biogeochemical cycling of trace metals. This entails that trace metal concentrations may have a stronger influence on microalgae inhabiting inshore ecosystems rather than organisms thriving in the open ocean or offshore ecosystems.

\section{Effect of Fe Availability on S. kawagutii Growth in Continuous Cultures}

In our previous work, we have established that $S$. kawagutii requires $500 \mathrm{pM} \mathrm{Fe}^{\prime}$ to sustain high growth rates under batch culture conditions (Rodriguez et al., 2016). Although batch cultures offer an efficient and convenient way of studying the interactive effects of trace metals on algal growth, the diminishing availability of major nutrients and vitamins during the incubation 
period also influence trace metal requirements. Continuous cultures represent a better simulation of natural conditions in terms of mimicking the conditions of micronutrient and major nutrient supplies (Lippemeier et al., 2001). The use of continuous cultures also allows maintenance of microalgae in a steady state growth condition wherein the growth rate is regulated by controlling the flow rates of both inflow of fresh medium and outflow of culture medium. Prior to the steady state growth period, which is called the establishment phase, algal cells in continuous culture grow in similar performance as that in batch culture and growth rates may be higher than both flow rates (Gresham and Hong, 2014). Once in steady state growth period, the growth rate of algal cells is equivalent to the flow rate, which ideally should be equivalent for both inflow and outflow, divided by the volume of the growth medium (Herbert et al., 1956; Touloupakis et al., 2015). To ensure that we only observe the influence of Fe availability, we carried out the continuous culture experiments by only varying $\mathrm{Fe}^{\prime}$ under exactly same flow rates and all other growth conditions were identical. Our results validated our previous observation that $500 \mathrm{pM} \mathrm{Fe}$ supports optimum growth of S. kawagutii as demonstrated by high cell density attained in this treatment when cultures reached steady state condition (Figure 4A). The cultures with $1.25 \mathrm{nM} \mathrm{Fe}^{\prime}$ attained comparable cell densities to cultures with $500 \mathrm{pM} \mathrm{Fe}^{\prime}$ and reached steady state growth a week earlier, indicating that higher Fe supply leads to a shorter establishment phase of S. kawagutii. The cultures with $250 \mathrm{pM} \mathrm{Fe}^{\prime}$ achieved steady state condition at lower cell density, suggesting that insufficient Fe concentration inhibited the proliferation of S. kawagutii. Endosymbionts in the coral Acropora millepora have been reported to reach densities of $1.4 \times 10^{6}$ cells $\mathrm{cm}^{-2}$, which corresponded to a Symbiodinium to host cell ratio of 15 to 100 (Mieog et al., 2009). The observed cell densities in treatments with higher Fe indicate that symbiotic dinoflagellates may require high bioavailable Fe concentrations to sustain high cell densities in intact holobionts. This highlights the need to study the Fe trafficking, and also that of other metals, within the coral holobiont.

The growth of the dinoflagellate in continuous culture was also studied under a slight increase in growth temperature, which was done from days 17 to 23 by rapidly increasing the temperature to $28^{\circ} \mathrm{C}$, an increase of $2^{\circ} \mathrm{C}$ from the ambient temperature. It has been reported that prolonged exposure to temperatures that are $2^{\circ} \mathrm{C}$ higher than the average monthly maximum may lead to coral bleaching (Jokiel and Coles, 1990). Although the exposure to higher temperature only lasted for 1 week, this may offer insights into how free-living dinoflagellate responds to a sudden increase in temperature. In this study, we observed that $500 \mathrm{pM}$ and $1.25 \mathrm{nM} \mathrm{Fe}$ conditions were able to sustain the dinoflagellate growth during the temperature change. We propose that sufficient Fe supply sustains growth of $S$. kawagutii during sudden pulses of temperature increases. This has important implications in the resilience of hostdinoflagellate associations because $\mathrm{Fe}$ availability within the holobiont may influence the capability of Symbiodinium to cope with temperature stress by producing Fe-containing antioxidative enzymes.

\section{Metal-Metal Interaction in S. kawagutii}

Intracellular metal quotas of $S$. kawagutii show that the dinoflagellate takes up high concentrations of $\mathrm{Fe}$, followed by $\mathrm{Mn}, \mathrm{Zn}, \mathrm{Cu}, \mathrm{Ni}$, and $\mathrm{Co}$ in the control treatment (Figure 3B). In this set of treatments with lower $\mathrm{Cu}$ and $\mathrm{Zn}$ concentrations, $\mathrm{Zn}$ and $\mathrm{Cu}$ quotas were comparable in cultures supplied with both metals. These results suggest that intracellular uptake for both metals were equivalent despite the dissimilarity of their effect on S. kawagutii growth (Figure 3A). In treatments lacking Zn, independently or in combination with other metals, we observed the significant elevation of intracellular quotas of $\mathrm{Fe}, \mathrm{Mn}, \mathrm{Ni}$, and $\mathrm{Co}$, particularly $\mathrm{Fe}$ (Figures 2, 3B and Supplementary Figure 3C). The elevation in quotas of other divalent metals was also observed in the low $\mathrm{Cu} / \mathrm{Zn}$ treatment in our previous study (Rodriguez et al., 2016). Our results demonstrate that this increase was largely due to $\mathrm{Zn}$ limitation as there were no elevated intracellular quotas observed in treatments lacking $\mathrm{Cu}$. Further examination of results indicates that increase in quotas was indeed ascribed to $\mathrm{Zn}$ limitation. For example, Fe and $\mathrm{Mn}$ quotas were elevated in $-\mathrm{Zn}$ and $-\mathrm{Zn} / \mathrm{Co}$ but not in Co cultures, and $\mathrm{Fe}$ and $\mathrm{Ni}$ quotas were elevated in $-\mathrm{Zn}$ and - Mn/Zn but not in -Mn cultures. It is tempting to attribute the increase in quotas of divalent cations to activity of nonspecific metal transporters (Lane et al., 2008). However, the increase may also be caused by biological requirement or metal replacement in specific biological processes. For instance, the elevated $\mathrm{Fe}$ and $\mathrm{Mn}$ quotas in low $\mathrm{Zn}$ conditions may be due to increased production of Fe- or Mn-containing enzymes required in pertinent photosynthetic systems and anti-oxidative defense networks (Sunda, 2012). Also, the observed elevation in Co quotas may be related to activity of carbonic anhydrase. Among Zn-requiring metalloproteins, carbonic anhydrase, the enzyme that catalyzes the reversible reaction between bicarbonate and free $\mathrm{CO}_{2}$, is arguably the most important (Sunda, 2012). The metal cofactor of carbonic anhydrase in diatoms may be replaced by either Co or Cd (Price and Morel, 1990; Sunda and Huntsman, 1995). The elevated Co quotas in low Zn conditions hint at the possibility of Co replacement for $\mathrm{Zn}$, which may be beneficial for S. kawagutii especially in Zn limited conditions. Typical $\mathrm{Zn}$ concentrations in the surface water of the open ocean are relatively low, generally ranging from 0.3 to $2 \mathrm{nM}$ and its bioavailability is further reduced by strong complexation with naturally occurring organic ligands (Bruland, 1989; Crawford et al., 2003). Future studies are needed to examine bioavailable $\mathrm{Zn}$ concentrations and evaluate the importance of $\mathrm{Zn}$ as a limiting factor for Symbiodinium in coral reef areas.

In the continuous culture study, the metal quotas show that intracellular $\mathrm{Fe}$ quotas were slightly higher in the treatment with $250 \mathrm{pM} \mathrm{Fe}^{\prime}$ than in treatments with $500 \mathrm{pM}$ and $1.25 \mathrm{nM}$ $\mathrm{Fe}^{\prime}$ despite having lower cell density throughout the incubation period. The higher intracellular Fe content may be attributed to reduced growth dilution because of lower cell density in the treatment with $250 \mathrm{pM} \mathrm{Fe}^{\prime}$ (Sunda and Huntsman, 1998). Among all of the metal quotas determined, intracellular Mn quotas exhibited the least variation among the three treatments while $\mathrm{Ni}$ and Co quotas were slightly higher in cultures with $250 \mathrm{pM}$ 
$\mathrm{Fe}^{\prime}$ than in the other two treatments. The elevation in $\mathrm{Ni}$ and $\mathrm{Co}$ quotas may be related to uptake of non-specific divalent metal transporters when Fe is limited in culture medium (Lane et al., 2008). In addition, $\mathrm{Cu}$ quotas were lowest in cultures with 250 pM Fe'. The interactive effects of $\mathrm{Cu}$ and $\mathrm{Fe}$ on phytoplankton growth and succession have been studied in diverse organisms (Maldonado et al., 2006; Semeniuk et al., 2016). There are at least two biological roles associated with $\mathrm{Cu}$ including the involvement of $\mathrm{Cu}$ in high-affinity $\mathrm{Fe}$ transport systems of some diatoms and the use of $\mathrm{Cu}$-containing plastocycanin instead of $\mathrm{Fe}$ containing cytochrome $\mathrm{c}_{6}$ in Thalassiosira oceanica (Maldonado et al., 2006; Peers and Price, 2006). Our results show that low $\mathrm{Fe}$ availability did not elicit an increase in $\mathrm{Cu}$ quotas, indicating that $\mathrm{Fe}-\mathrm{Cu}$ interaction in $\mathrm{S}$. kawagutii may be owed to other biological processes or uptake exclusion by same transporters. The last and most notable trend was pertaining to $\mathrm{Zn}$ quotas in cultures supplied with $250 \mathrm{pM} \mathrm{Fe}$, which reflected higher values during the period of higher growth temperature. $\mathrm{Cu} / \mathrm{Zn}$ $\mathrm{SOD}$ is an important anti-oxidative enzyme. Increase in $\mathrm{Zn}$ quotas may be attributed to increased requirement for $\mathrm{Cu} / \mathrm{Zn}$ $\mathrm{SOD}$ at higher growth temperature. However, corresponding $\mathrm{Cu}$ quotas were not elevated, which underscores the need to include complementary determination of protein level information with intracellular metal content in future studies. For instance, parallel information on SOD expression may shed light on how the dinoflagellate utilizes various SODs when it is grown in media with different availability of metal cofactors.

\section{CONCLUSION}

The growth rates and intracellular metal quotas observed in this study provide an insight on the trace metal requirements and metal interactions in S. kawagutii. In this work, we have elucidated the effect of different trace metals, including $\mathrm{Fe}, \mathrm{Cu}$, $\mathrm{Zn}, \mathrm{Mn}, \mathrm{Co}$, and $\mathrm{Ni}$, on the growth of S. kawagutii and established the relative intracellular requirements of the dinoflagellate. In addition, we demonstrated the use of continuous cultures to elucidate the influence of Fe availability and study metal-metal

\section{REFERENCES}

Bruland, K. W. (1989). Complexation of zinc by natural organic ligands in the central North Pacific. Limnol. Oceanogr. 34, 269-285. doi: 10.4319/lo.1989.34.2. 0269

Cao, C., Sun, S., Wang, X., Liu, W., and Ling, Y. (2011). Effects of manganese on the growth, photosystem II and SOD activity of the dinoflagellate Amphidinium sp. J. Appl. Phycol. 23, 1039-1043. doi: 10.1007/s10811-0109637-0

Crawford, D. W., Lipsen, M. S., Purdie, D. A., Lohan, M. C., Statham, P. J., Whitney, F. A., et al. (2003). Influence of zinc and iron enrichments on phytoplankton growth in the Northeastern Subarctic Pacific. Limnol. Oceanogr. 48, 1583-1600. doi: 10.4319/lo.2003.48.4.1583

Donat, J. R., Lao, K. A., and Bruland, K. W. (1994). Speciation of dissolved copper and nickel in South San Francisco Bay: a multi-method approach. Anal. Chim. Acta 284, 547-571. doi: 10.1016/0003-2670(94)85061-5

Dunstan, W. M., and Menzel, D. W. (1971). Continuous cultures of natural populations of phytoplankton in dilute, treated sewage effluent. Limnol. Oceanogr. 16, 623-632. doi: 10.4319/lo.1971.16.4.0623 interaction in S. kawagutii. Our results offer distinctive and useful primary information into the complex and interconnected processes utilizing metals in free-living Symbiodinium. Also, these results may be valuable to infer on the trace metal requirements of symbiotic dinoflagellates existing within the holobiont where supply of trace metals and other nutrients depend on the host. For future studies on free-living or symbiotic Symbiodinium species, it will be beneficial to obtain parallel information about metal-containing proteins and genes expression with their growth rates and intracellular metal content for a better understanding of the biochemical functions of trace metals in Symbiodinium.

\section{AUTHOR CONTRIBUTIONS}

IR and T-YH designed the study, analyzed the data, and wrote the manuscript; IR performed the experiments.

\section{FUNDING}

This research was financially supported by Taiwan Ministry of Science and Technology grant numbers 106-2611-M-001-003 and 105-2119-M-001-039-MY3, and Career Development Award from Academia Sinica.

\section{ACKNOWLEDGMENTS}

The authors thank C. S. Juanico, J. Ho, C. Chern, and R. A. Magbitang for technical support and H. G. Reich for proofreading the manuscript.

\section{SUPPLEMENTARY MATERIAL}

The Supplementary Material for this article can be found online at: https://www.frontiersin.org/articles/10.3389/fmicb. 2018.00142/full\#supplementary-material

Festa, R. A., and Thiele, D. J. (2011). Copper: an essential metal in biology. Curr. Biol. 21, R877-R883. doi: 10.1016/j.cub.2011.09.040

Goiran, C., Al-Moghrabi, S., Allemand, D., and Jaubert, J. (1996). Inorganic carbon uptake for photosynthesis by the symbiotic coral/dinoflagellate association I. Photosynthetic performances of symbionts and dependence on sea water bicarbonate. J. Exp. Mar. Biol. Ecol. 199, 207-225. doi: 10.1016/0022-0981(95) 00201-4

Gresham, D., and Hong, J. (2014). The functional basis of adaptive evolution in chemostats. FEMS Microbiol. Rev. 39, 2-16. doi: 10.1111/1574-6976.12082

Guillard, R. R. L., and Hargraves, P. E. (1993). Stichochrysis immobilis is a diatom, not a chrysophyte. Phycologia 32, 234-236. doi: 10.2216/i0031-8884-32-3-234.1

Herbert, D., Elsworth, R., and Telling, R. C. (1956). The continuous culture of bacteria; a theoretical and experimental study. J. Gen. Microbiol. 14, 601-622. doi: 10.1099/00221287-14-3-601

Ho, T.-Y. (2013). Nickel limitation of nitrogen fixation in Trichodesmium. Limnol. Oceanogr. 58, 112-120. doi: 10.4319/lo.2013.58.1.0112

Ho, T.-Y., Quigg, A., Finkel, Z. V., Milligan, A. J., Wyman, K., Falkowski, P. G., et al. (2003). The elemental composition of some marine phytoplankton. J. Phycol. 39, 1145-1159. doi: 10.1111/j.0022-3646.2003.03-090.x 
Jokiel, P. L., and Coles, S. L. (1990). Response of Hawaiian and other IndoPacific reef corals to elevated temperature. Coral Reefs 8, 155-162. doi: 10.1007/ BF00265006

Krediet, C. J., DeNofrio, J. C., Caruso, C., Burriesci, M. S., Cella, K., and Pringle, J. R. (2015). Rapid, precise, and accurate counts of Symbiodinium cells using the Guava Flow Cytometer, and a comparison to other methods. PLOS ONE 10:e0135725. doi: 10.1371/journal.pone.0135725

Lage, O. M., Parente, A. M., Soares, H. M. V. M., Vasconcelos, M. T. S. D., and Salema, R. T. (1994). Some effects of copper on the dinoflagellates Amphidinium carterae and Prorocentrum micans in batch culture. Eur. J. Phycol. 29, 253-260. doi: 10.1080/09670269400650711

Landing, W. M., and Bruland, K. W. (1987). The contrasting biogeochemistry of iron and manganese in the Pacific Ocean. Geochim. Cosmochim. Acta 51, 29-43.

Lane, E. S., Jang, K., Cullen, J. T., and Maldonado, M. T. (2008). The interaction between inorganic iron and cadmium uptake in the marine diatom Thalassiosira oceanica. Limnol. Oceanogr. 53, 1784-1789. doi: 10.4319/lo.2008. 53.5.1784

Lippemeier, S., Hintze, R., Vanselow, K. H., Hartig, P., and Colijn, F. (2001). Inline recording of PAM fluorescence of phytoplankton cultures as a new tool for studying effects of fluctuating nutrient supply on photosynthesis. Eur. J. Phycol. 36, 89-100. doi: 10.1080/09670260110001735238

Maldonado, M. T., Allen, A. E., Chong, J. S., Lin, K., Leus, D., Karpenko, N., et al. (2006). Copper-dependent iron transport in coastal and oceanic diatoms. Limnol. Oceanogr. 51, 1729-1743. doi: 10.4319/lo.2006.51.4.1729

Mieog, J. C., Van Oppen, M. J., Stam, W. T., and Olsen, J. L. (2009). Quantification of algal endosymbionts (Symbiodinium) in coral tissue using real-time PCR. Mol. Ecol. Resour. 9, 74-82. doi: 10.1111/j.1755-0998.2008.02222.x

Morel, F. M. M., and Price, N. M. (2003). The biogeochemical cycles of trace metals in the oceans. Science 300, 944-947. doi: 10.1126/science.1083545

Peers, G., and Price, N. M. (2006). Copper-containing plastocyanin used for electron transport by an oceanic diatom. Nature 441, 341-344. doi: 10.1038/ nature 04630

Pochon, X., Montoya-Burgos, J. I., Stadelmann, B., and Pawlowski, J. (2006). Molecular phylogeny, evolutionary rates, and divergence timing of the symbiotic dinoflagellate genus Symbiodinium. Mol. Phylogenet. Evol. 38, 20-30. doi: 10.1016/j.ympev.2005.04.028

Price, N. M., and Morel, F. M. M. (1990). Cadmium and cobalt substitution for zinc in a marine diatom. Nature $344,658-660$. doi: 10.1038/344658a0

Rädecker, N., Pogoreutz, C., Voolstra, C. R., Wiedenmann, J., and Wild, C. (2015). Nitrogen cycling in corals: the key to understanding holobiont functioning? Trends Microbiol. 23, 490-497. doi: 10.1016/j.tim.2015.03.008

Raven, J. A., Evans, M. C. W., and Korb, R. E. (1999). The role of trace metals in photosynthetic electron transport in $\mathrm{O}_{2}$-evolving organisms. Photosynth. Res. 60, 111-149. doi: 10.1023/A:1006282714942
Rodriguez, I. B., Lin, S., Ho, J., and Ho, T.-Y. (2016). Effects of trace metal concentrations on the growth of the coral endosymbiont Symbiodinium kawagutii. Front. Microbiol. 7:82. doi: 10.3389/fmicb.2016. 00082

Saifullah, S. M. (1978). Inhibitory effects of copper on marine dinoflagellates. Mar. Biol. 44, 299-308. doi: 10.1007/BF00390893

Semeniuk, D. M., Taylor, R. L., Bundy, R. M., Johnson, W. K., Cullen, J. T., Robert, M., et al. (2016). Iron-copper interactions in iron-limited phytoplankton in the northeast subarctic Pacific Ocean. Limnol. Oceanogr. 61, 279-297. doi: 10.1002/lno.10210

Sholkovitz, E. R., Sedwick, P. N., and Church, T. M. (2010). On the fractional solubility of copper in marine aerosols: Toxicity of aeolian copper revisited. Geophys. Res. Lett. 37:L20601.

Stat, M., Morris, E., and Gates, R. D. (2008). Functional diversity in coraldinoflagellate symbiosis. Proc. Natl. Acad. Sci. U.S.A. 105, 8256-8261. doi: $10.1073 /$ pnas.0801328105

Sunda, W. G. (2012). Feedback interactions between trace metal nutrients and phytoplankton in the ocean. Front. Microbiol. 3:204. doi: 10.3389/fmicb.2012. 00204

Sunda, W. G., and Huntsman, S. A. (1995). Cobalt and zinc interreplacement in marine phytoplankton: biological and geochemical implications. Limnol. Oceanogr. 40, 1404-1417. doi: 10.4319/lo.1995.40.8.1404

Sunda, W. G., and Huntsman, S. A. (1998). Processes regulating cellular metal accumulation and physiological effects: phytoplankton as model systems. Sci. Total Environ. 219, 165-181. doi: 10.1016/S0048-9697(98) 00226-5

Touloupakis, E., Cicchi, B., and Torzillo, G. (2015). A bioenergetic assessment of photosynthetic growth of Synechocystis sp. PCC 6803 in continuous cultures. Biotechnol. Biofuels 8:133. doi: 10.1186/s13068-015-0319-7

Westall, J. C., Zachary, J. L., and Morel, F. M. M. (1976). A Computer Program for the Calculation of Chemical Equilibrium Composition of Aqueous Systems, Civil Engineering Technology Note 18. Cambridge, MA: Massachusetts Institute of Technology.

Conflict of Interest Statement: The authors declare that the research was conducted in the absence of any commercial or financial relationships that could be construed as a potential conflict of interest.

Copyright (c) 2018 Rodriguez and Ho. This is an open-access article distributed under the terms of the Creative Commons Attribution License (CC BY). The use, distribution or reproduction in other forums is permitted, provided the original author(s) and the copyright owner are credited and that the original publication in this journal is cited, in accordance with accepted academic practice. No use, distribution or reproduction is permitted which does not comply with these terms. 